\title{
Enhancing the Efficacy of Albendazole for Liver Cancer Treatment Using Mesoporous Silica Nanoparticles: An In Vitro Study
}

Mohsen Ghaferi

Rafsanjan University of Medical Sciences

Syeda Warda Zahra

Nishtar Medical University and Hospital

Hasan Ebrahimi Shahmabadi ( $\nabla$ ebrahimi@rums.ac.ir)

Rafsanjan University of Medical Sciences https://orcid.org/0000-0001-5222-3829

Seyed Ebrahim Alavi

Rafsanjan University of Medical Sciences

\section{Research Article}

Keywords: Albendazole, Cancer, Drug delivery, MCM-41, Mesoporous silica nanoparticles

Posted Date: March 15th, 2021

DOI: https://doi.org/10.21203/rs.3.rs-294729/v1

License: (c) (i) This work is licensed under a Creative Commons Attribution 4.0 International License. Read Full License 


\section{Abstract}

The present study aimed to synthesize albendazole (ABZ)-loaded Mobil Composition of Matter No. 41 (MCM-41) nanoparticles (NPs) to increase the efficacy of the drug against liver cancer. ABZ was loaded into MCM-41 NPs, and after in vitro characterization, such as size, size distribution, zeta potential, morphology, chemical composition, thermal profile, drug release, surface and pore volume, and pore size, their biological effects were evaluated using 3-[4,5-dimethylthiazol-2-yl]-2,5 diphenyl tetrazolium bromide (MTT) cell migration assays. The results demonstrated that monodispersed and spherical NPs with a size of $220 \pm 11.5$ and $293 \pm 8.7 \mathrm{~nm}$, for MCM-41 NPs and ABZ-loaded MCM-41 NPs, respectively, and drug loading efficiency of $30 \%$ were synthesized. ABZ was loaded physically into MCM-41 NPs, leading to a decrease in surface volume, pore size, and pore volume. Also, MCM-41 NPs could increase the cytotoxicity effects of $A B Z$ by 2.9 -fold $\left(\mathrm{IC}_{50}=23\right.$ and $7.9 \mu \mathrm{M}$ for $\mathrm{ABZ}$ and ABZ-loaded MCM-41 NPs, respectively). In addition, ABZ-loaded MCM- 41 NPs, compared to that of ABZ, caused a significant decrease in cell migration. Overall, the results of the present study suggest evaluating the potency of MCM-41 NPs, as a potent nanoplatform, for ABZ delivery in vivo environment.

\section{Introduction}

Liver cancer is the fifth most common cancer and the second cancer in terms of mortality in the world $(35,42)$. The number of new cases and deaths from liver cancer was 841,080 and 781,631 , respectively, in 2018 (10). Liver cancer has poor prognosis, mainly due to the diagnosis in many cases is made late or inaccurate $(30,40,1)$. The five-year survival rate in liver cancer is poor and is less than $20 \%(19)$. Moreover, the recurrence rate of liver cancer following surgery is high equal to $70-80 \%(16,13)$. Various types of treatment have been used for liver cancer, including surgical resection and chemotherapy (51).

Albendazole (ABZ) is a benzimidazole carbamate with anthelmintic activity. It functions through targeting and destruction of the $\beta$-tubulin structure to restrain the microtubule polymerization (36). Recent studies have demonstrated that $A B Z$ can restrain microtubule polymerization, and this can cause anti-tumor activity against various tumors, such as liver cancer $(36,50)$. Moreover, scientists have demonstrated that ABZ can cause a significant decrease in the activity of hypoxia-inducible factor-la (HIF-1a) and vascular endothelial growth factor (VEGF) in ovarian cancer, that restrains tumor angiogenesis, and as a result, decreasing the symptoms of ascites (45). ABZ has also been found as a radiosensitizer in tumor models (e.g., metastatic melanoma and small cell lung cancer) as it can induce DNA damage (47).

Despite the wide range of applications, the use of $A B Z$ is restricted owing to low water solubility $(2.7 \mu M)$, which leads to negligible or variable bioavailability following administration (14). Many efforts have been made to overcome this barrier, such as the use of various solvent, (28) solid dispersion, (39) and microparticles and nanoparticles (NPs). Among all of these strategies, the most successful ones are developing the formulations of ABZ using nanocomplexes and NPs (14). 
NPs are potent to enhance the efficacy of drugs $(43,5)$ and reduce their adverse side effects $(20)$. Various NPs have been used for the delivery of anticancer drugs $(33,17)$. In this regard, mesoporous silica NPs (MSNPs) have drawn considerable attention as controlled drug delivery systems (38).

MSNPs are solid materials, containing hundreds of arranged empty mesopores with a high capacity of loading for hydrophobic and hydrophilic drugs (52). They are cost-effective nanomaterials with low toxicity, tunable pore size, and simple fabrication method $(34,55)$. Their surface can be readily functionalized (14) to improve their cellular uptake. Due to several attractive properties, such as large surface area and pore volume, as well as long regular pore structure, MSNPs are able to improve drug solubility. Also, these carriers, compared to various other polymers utilized to increase drug solubility, have demonstrated higher thermal resistance, higher levels of resistance to $\mathrm{pH}$, and superior stability on storage. The porous structure of MS materials allows them to confine and stabilize the amorphous state of drug molecules within the pores rather than the crystalline state, resulting in an increase in the solubility rate of the drug molecules $(3,22)$. To synthesize MSNPs, a surfactant micelle is used as a template to direct the polymerization of silica components (scheme 1) (41). MSNPs are successfully utilized for oral delivery of hydrophobic drugs, where they can cause an improvement in the dissolution rate and bioavailability of these drugs (58).

Scheme 1. Schematic diagram of the mechanism of ABZ-MCM-41 NP synthesis. CTAB is a cationic surfactant micelle and functions as a template for directing the polymerization of silica component (TEOS). The resulting mixture (CTAB+TEOS) is then crystallized under the hydrothermal condition, and the solid product (hexagonal structure) is generated. The solid product is then calcinated to remove CTAB, resulting in the final product (MCM-41 pores structure). The product is then loaded with ABZ, and ABZMCM-41 NPs are produced.

The low water solubility of drugs causes their low absorption, and as a result, their low bioavailability (11), which, in turn, can lead to a significant decrease in the therapeutic response and an increase in the overall dose (2). ABZ due to low water solubility has low bioavailability after oral administration $(56,48)$. The present study aimed to provide a nanoplatform of ABZ using MSNPs with an enhanced therapeutic response against liver cancer. For this purpose, ABZ was loaded into the Mobil Composition of Matter No. 41 (MCM-41) NPs, which are high ordered mesoporous materials (61). Next, the in vitro characterization of ABZ-loaded NPs was conducted in terms of size, size distribution, zeta potential, morphology, chemical bonds, specific surface area, thermal stability using dynamic light scattering (DLS), scanning (SEM) and transmission (TEM) electron microscopy, Fourier transform-infrared (FT-IR), Brunauer-Emmett-Teller (BET), differential scanning calorimetry (DSC) and thermogravimetric analysis (TGA) methods, respectively. The efficacy of ABZ either in the encapsulated form in MCM-41 NPs or free form was evaluated on HepG2 cells using 3-[4,5-dimethylthiazol-2-yl]-2,5 diphenyl tetrazolium bromide (MTT) and cell migration assays.

\section{Experimental Section}




\section{Materials}

$\mathrm{N}$-cetyltrimethylammonium bromide (CTAB), dimethylsulfoxide (DMSO), tetraethylorthosilicate (TEOS), acetone, sodium hydroxide $(\mathrm{NaOH})$, phosphate-buffered saline (PBS), MTT, and ABZ were purchased from Merck (Darmstadt, Germany). Roswell Park Memorial Institute (RPMI)-1640 medium, Pen/Strep antibiotics, and fetal bovine serum (FBS) were purchased from Gibco (Waltham, MA, USA). Human liver cancer HepG2 cells were supplied from the Pasteur Institute of Iran (Tehran, Iran). All of the materials were used as they received.

\section{Synthesis of MCM-41}

To synthesize MCM-41 NPs, $1 \mathrm{~g}$ of CTAB was added to $480 \mathrm{~mL}$ MilliQ water and stirred (700 RPM, room temperature) to obtain a clear solution. Next, $\mathrm{NaOH}$ solution $(3.5 \mathrm{~mL}, 2 \mathrm{M})$ was added $(1 \mathrm{~mL} / \mathrm{min})$ to the solution, and the mixture was heated to $80^{\circ} \mathrm{C}$ using an oil bath under continuous stirring. While heating, $6.7 \mathrm{~mL}$ of TEOS was added ( $1 \mathrm{~mL} / \mathrm{min}$ ) to the mixture, stirred (700 RPM, $2 \mathrm{~h}$ ), and vacuum filtered. The solution was then washed with MilliQ water three times, and to dry the resulting precipitate, it was put in an oven at $60{ }^{\circ} \mathrm{C}$ overnight. The dried precipitate was crushed and heated to $550{ }^{\circ} \mathrm{C}$ for $5 \mathrm{~h}$ using a muffle furnace to remove any remaining of the surfactant (CTAB).

\section{Drug loading into MCM-41}

Forty milligrams of $A B Z$ was dissolved in $50 \mathrm{~mL}$ of acetone using a bath sonicator ( $50 \mathrm{~Hz}, 5 \mathrm{~min}$ ). Next, $160 \mathrm{mg}$ of MCM-41 NPs was added to the mixture and stirred (overnight, room temperature). The organic solvent was then removed using a rotary evaporator $\left(40^{\circ} \mathrm{C}\right)$. The drug-loaded nanoparticles were scratched off from the bottom of the vessel.

\section{Characterization of nanoparticles}

Dynamic light scattering

The size, size distribution, and zeta potential of MCM-41 and ABZ-loaded MCM-41 NPs were determined using Zetasizer instrument (Malvern, UK). For this purpose, a suspension of both nanoparticles (100 $\mu \mathrm{g} / \mathrm{mL}$ ) was provided in PBS ( $\mathrm{pH}$ 7.4) using a bath sonicator (10 min), and the suspensions were introduced to the instrument.

\section{Transmission electron microscopy}

The morphology of ABZ-loaded MCM-41 NPs was studied using TEM (Zeiss, EM10C, 80 kV, Oberkochen, Germany). For this purpose, $20 \mu \mathrm{L}$ of the nanoparticles suspension was placed on a copper grid and imaged.

Scanning electron microscopy 
The morphology of ABZ-loaded MCM-41 NPs was evaluated using SEM XL30 Philips (Eindhoven, The Netherlands) in a high vacuum mode. The nanoparticles were first coated with gold and then evaluated by the SEM instrument.

Fourier transformed infrared spectroscopy

The structure and chemical composition of MCM-41 NPs before and after loading with ABZ were characterized by FTIR spectroscopy (Bruker FRA model 106/5). The KBr tablets with KBr:ABZ, KBr:MCM-41 NPs, and KBr:ABZ-loaded MCM-41 NPs ratio of 100:1 were provided, and the related FTIR spectra were obtained in a frequency range of $400-4000 \mathrm{~cm}^{-1}$.

Thermogravimetric analysis and differential scanning calorimetry

Five milligrams of ABZ, MCM-41 NPs, and ABZ-loaded MCM-41 NPs were characterized in terms of thermal properties and thermal composition using a TGA/DSC Instruments LINSIES STP PT-1000 with a heating rate of $10^{\circ} \mathrm{C} / \mathrm{min}$ and under an air ambient.

Drug release from nanoparticles

ABZ-loaded MCM-41 NPs (equal to $0.3 \mathrm{mg} \mathrm{ABZ)} \mathrm{were} \mathrm{suspended} \mathrm{in} 5 \mathrm{~mL}$ PBS (pH 1.9 and 7.4) and stirred at $200 \mathrm{RPM}$ at room temperature. At various time intervals $(0.25,0.5,1,2,4,6,8,10,12 \mathrm{~h}), 50 \mu \mathrm{L}$ was taken out and centrifuged. The drug concentrations in the samples were measured using the highperformance liquid chromatography (HPLC) method. Next, the cumulative drug release was calculated using the following equation:

$$
\text { Drug release }(\%)=\frac{\text { Release drug from particles }(\mathrm{mg})}{\text { Total drug in particles }(\mathrm{mg})} \times 100
$$

The kinetics of the drug release was then determined using mathematical models, including zero-order, first-order, Higuchi and Korsmeyer-Peppas models $(54,53)$.

Brunauer-Emmett-Teller surface area analysis

The total surface area and pore size distribution of MCM-41 NPs before and after loading with ABZ were measured by a surface area and pore size analyzer (BELsorp-mini II, Japan) and Barrett-Joyner-Halenda (BJH) methods. For this purpose, $70 \mathrm{mg}$ of MSNPs and ABZ-loaded MCM-41 NPs were degassed prior to analysis. BET surface area and pore size were then measured by $\mathrm{N}_{2}$ adsorption using a surface area and pore size analyzer (BELsorp-mini II, Japan).

\section{Biological effects of the nanoparticles}

Cytotoxicity studies 
The cytotoxicity effects of ABZ-loaded MCM-41 NPs compared to ABZ were evaluated using an MTT assay, as described previously (6). For this purpose, HepG2 cells were cultured in RPMI-1640 medium supplemented with $10 \%$ FBS and $1 \%$ penicillin/streptomycin antibiotics in a 96-well plate at a density of $10^{4}$ cells/well. After $24 \mathrm{~h}$ incubation in a humidified incubator $\left(37^{\circ} \mathrm{C}, 5 \% \mathrm{CO}_{2}\right)$, the media were discarded, and the cells were treated with ABZ and ABZ-loaded MCM-41 NPs at the drug concentrations of 0, 3.1, $6.3,12.5,25,50$, and $100 \mu \mathrm{M}$. The plates were incubated $\left(5 \% \mathrm{CO}_{2}, 37^{\circ} \mathrm{C}\right)$ for $24 \mathrm{~h}$, and the media were replaced with MTT solution ( $100 \mu \mathrm{L}, 0.5 \mathrm{mg} / \mathrm{mL}$ PBS). After $4 \mathrm{~h}$ incubation $\left(5 \% \mathrm{CO}_{2}, 37^{\circ} \mathrm{C}\right)$, the MTT solution was removed, and $100 \mu \mathrm{L}$ of DMSO was added to each well to dissolve the formazan crystals. After 20 min incubation $\left(5 \% \mathrm{CO}_{2}, 37^{\circ} \mathrm{C}\right)$, the absorbance was measured at $540 \mathrm{~nm}$ using a microplate scanning spectrophotometer (ELISA reader, Organon Teknika, Boxtel, the Netherlands), and the cell viability was measured using the formula below.

\section{Cell viability $(\%)=\frac{\text { Absorbance }_{\text {sample }}-\text { Absorbance }_{\text {background }}}{\text { Absorbance }_{\text {negative control }}-\text { Absorbance }_{\text {background }}} \times 100$}

where negative control and background were the treated cells with only media, and only media, respectively.

Cell migration

To evaluate the effects of the standard ABZ and ABZ-loaded MCM-41 NPs on HepG2 cell migration, the cells were cultured in 12-well plates containing RPMI 1640 medium. At 90-95\% confluency, the scratches were introduced onto the monolayer cell surfaces by a $200 \mu \mathrm{L}$ sterile pipette tip, and a cell-free area was developed. The cellular debris was removed by gentle washing using a culture medium, and the scratches were imaged $(0 \mathrm{~h})$. Next, the media were discarded, and the cells were treated in triplicate with the standard ABZ and ABZ-loaded MCM-41 NPs at the drug concentrations of $25 \mu \mathrm{M}$. The plates were then incubated $\left(5 \% \mathrm{CO}_{2}, 37^{\circ} \mathrm{C}\right)$ for $24 \mathrm{~h}$. The scratches were imaged after $24 \mathrm{~h}$, and their area in each well was measured and analyzed.

\section{Statistical analysis}

All statistical analyses were performed using GraphPad Prism software version 8.00. Size, size distribution, drug loading efficiency, $\mathrm{N}_{2}$ adsorption, cell viability data, and cell migration date were expressed as the mean \pm standard deviation (SD, $n=3$ ). Statistical differences were analyzed by oneway analysis of variance (ANOVA) test. Statistical analysis was performed using nonlinear regression analysis, and comparisons were made for the half-maximal inhibitory concentration $\left(\mathrm{IC}_{50}\right.$; the inhibitory concentration, which causes a decrease of $50 \%$ in cell growth compared with untreated control) values utilizing Tukey's test. 


\section{Results And Discussion}

\section{Characterization of nanoparticles}

Dynamic light scattering

MCM-41 NPs were successfully synthesized using CTAB, as a precursor, and TEOS, as the silicate source. The synthesized NPs were first characterized in terms of size. The size of NPs is a determinant factor affecting the efficiency of loaded therapeutics in that smaller NPs are more internalized into cells, thereby increasing the intracellular concentration of the loaded therapeutics (21). NPs with a size below $300 \mathrm{~nm}$ are efficiently internalized into target cells and exhibit their pharmaceutical effects (37). The resulting NPs, in the present study, were found with the size below $300 \mathrm{~nm}(220 \pm 11.5$ and $293 \pm 8.7 \mathrm{~nm}$, for MCM41 NPs and ABZ-loaded MCM-41 NPs, respectively, Fig. 1) (46, 59). Also, size distribution is a critical factor that affects various properties of NPs, such as biological effects, (27) reproducibility, (9) and stability (15). Particles with varying sizes have various properties in terms of i) blood circulation, ii) cellular uptake, and iii) biodistribution (27). Also, increasing the particle size and size distribution can result in the physical instability of NPs (15). The size distribution of MCM-41 and ABZ-loaded MCM-41 NPs were equal to 0.214 , and 0.282 , respectively, indicating that these NPs were homogenous and monodisperse $(57,26)$. Also, the zeta potential of NPs is an important factor to determine the stability of NPs suspension as NPs with the same charge (positive or negative) in aqueous solutions with low ionic strength repulse each other, and this restrains their aggregation (21). The zeta potential of MCM-41 and ABZ-loaded MCM-41 NPs were found to be $-36.3 \pm 4.57$ and $-33.0 \pm 4.93 \mathrm{mV}$, respectively.

Transmission electron microscopy

TEM was used to evaluate the size and structural features of ABZ-loaded MCM-41 NPs. The results of TEM confirmed the results of DLS and demonstrated that the NPs were synthesized at the nanoscale size. As Fig. 2a shows, the NPs were formed in uniform nanospheres with the hexagonal array of channels. Also, the porous structure of these NPs can be clearly observed.

Scanning electron microscopy

SEM was used to evaluate the surface morphology and size distribution of ABZ-loaded MCM-41 NPs. The SEM image of the NPs demonstrated that these particles were synthesized as homogenous and spherical NPs, which had a smooth surface (Fig. 2b). Also, it demonstrated that ABZ-loaded MCM-41 NPs were well dispersed without aggregation.

Fourier Transformed Infrared Spectroscopy

Fig. 3 demonstrates the FTIR spectroscopy of pure ABZ. The peak assigned to $3323 \mathrm{~cm}^{-1}$ was related to the stretching vibration mode of amide $\mathrm{N}-\mathrm{H}$. The absorption band observed at around $2960 \mathrm{~cm}^{-1}$ was related to the aliphatic hydrocarbon group $(\mathrm{C}-\mathrm{H})$. The ester $\mathrm{C}=\mathrm{O}$ bond of the carbamate portion was observed at about $1713 \mathrm{~cm}^{-1}$. The peak related to the aromatic $\mathrm{C}=\mathrm{C}$ bond was observed at around 
$1623 \mathrm{~cm}^{-1}$, which along with the amide $\mathrm{N}-\mathrm{H}$ bond, constitute the benzimidazole portion of the drug. The peak observed at around $1523 \mathrm{~cm}^{-1}$ indicated the stretching vibration mode of the $\mathrm{C}=\mathrm{N}$ group (3). Overall, the FTIR spectrum indicated normal bands of pure ABZ (3). Also, the bands related to asymmetric and symmetric Si-O-Si stretches of MCM-41 were observed at 1110 and $825 \mathrm{~cm}^{-1}$, respectively. A peak at around $980 \mathrm{~cm}^{-1}$ was also related to the tension of the $\mathrm{Si}-\mathrm{OH}$ bonds of the MCM-41 compound (23). The existence of $A B Z$ related peaks in ABZ-loaded NPs (e.g., $1623 \mathrm{~cm}^{-1}$, demonstrate by arrows in Fig. 3) confirmed that $A B Z$ was loaded into the NPs. According to the results, $A B Z$ preserved its chemical bonds in MCM-41 NPs, indicating the physical loading of ABZ into the NPs.

Thermogravimetric analysis and differential scanning calorimetry

To determine the drug loading efficiency and thermal stability of $A B Z$, the TGA curves (mass vs. temperature) of ABZ, MCM-41, and ABZ-loaded MCM-41 NPs were measured. According to the results (Fig. 4a), an initial weight loss occurred in MCM-41 NPs at around $250^{\circ} \mathrm{C}$ due to the evaporation of absorbed water molecules, indicating the hydrophilic nature of this carrier, which is an advantage for loading of poorly water-soluble drugs (32). Also, ABZ-loaded MCM-41 NPs started to be degraded at 150 ${ }^{\circ} \mathrm{C}$ and continued up to $900{ }^{\circ} \mathrm{C}$. This resulted in a mass loss of $30 \%$, which was related to the degradation of $A B Z$. Based on the results, the amount of $A B Z$ adsorbed onto the NPs was $30 \%$. ABZ was almost completely degraded at $900{ }^{\circ} \mathrm{C}$ (Fig. 4a).

DSC analysis can be used to investigate the existence or absence of a crystalline drug (e.g., ABZ) in the pores of mesoporous NPs $(4,29)$. Also, this method can be used to study the glass transition temperature $\left(T_{g}\right)$ of the samples, where at the temperature above $T_{g}$, various physical properties of a material, such as free molecular volume, heat capacity, thermal expansion coefficient, dielectric coefficient, and viscoelastic features, suddenly change $(32,8)$. Fig. $4 \mathrm{~b}$ illustrates the DSC profiles of the standard ABZ, MCM-41, and ABZ-loaded MCM-41 NPs. As MCM-41 NPs did not have any transitions in the temperature range of 50$350{ }^{\circ} \mathrm{C}$, only the thermal transition of $A B Z$ was observed (32). Thus, a melting endothermic peak at around $200{ }^{\circ} \mathrm{C}$ was observed in the thermogram of $A B Z$, which is indicative of a crystalline anhydrous state of the drug. Also, the DSC profile of ABZ-MCM-41 demonstrated a melting endothermic peak around $170{ }^{\circ} \mathrm{C}$, which was related to the crystalline anhydrous state of $A B Z$, confirming drug loading into NPs.

Drug release from nanoparticles

Several daily doses of a drug are needed to attain and preserve the therapeutic concentration of the drug. This might lead to significant fluctuations in the plasma concentration of the drug, (18) resulting in a decrease in the concentration beyond the minimum effective concentration, or an increase in the concentration above the minimum toxic concentration, and consequently, resulting in the lack of therapeutic effects or unfavorable toxic effects (21). These fluctuations in the plasma drug concentration can be reduced using sustained-release and controlled-release drug delivery systems, leading to improvements in the therapeutic outcome of the drug (49). 
In the present study, in order to simulate the $\mathrm{pH}$ changes in the gastrointestinal tract, the drug release was evaluated at $\mathrm{pH} 1.9$ and 7.4, corresponding to the $\mathrm{pH}$ values of the human stomach (31) and intestinal fluids (12), respectively. The results demonstrated that the release of ABZ from MCM-41 NPs was initiated with a burst release, in which in the first 15 min of the study, 62 and $70 \%$ of the loaded ABZ was released at $\mathrm{pH} 1.9$ and 7.4, respectively (Fig. 5). The burst drug release could stem from the release of the adsorbed drug onto the NPs or weakly bound between the drug and the NPs surface (20). In addition, by increasing the surface area of NPs, the amount of initial burst release increased (7). The pattern of the drug release continued with a gradually increasing trend at both $\mathrm{pH}$ values, in which 75 and $80 \%$ of the loaded drug were released after $12 \mathrm{~h}$, indicating a sustained and controlled drug release pattern.

Also, according to the results, the drug release was $\mathrm{pH}$-dependent; however, the difference in the amount of the drug release between two $\mathrm{pHs}$ was not statistically significant. These results were approximately similar to the results of Nguyen et al. study (44), where the difference in the amount of drug (prednisolone) release from MSNs at pH 1.9 and pH 7.4 was 2\%. In the current study, the difference in the amount of drug release in two $\mathrm{pHs}$ could be related to various factors, such as MSNPs agglomeration at acidic $\mathrm{pH}$ and variation in the surface charge of the nanoformulation in different $\mathrm{pH}(62,60)$. At acidic $\mathrm{pH}(\mathrm{pH}$ 1.9), the drug release from the pores of the agglomerated particles is inhibited, resulting in lower drug release (62). Also, to determine the kinetics of the drug release, the profiles of drug release were analyzed using different kinetic models, including zero and first order, Higuchi, and Korsmeyer Peppas models, and the correlation coefficient values were determined for the linear curves. Based on the results, the higher $\mathrm{R}^{2}$ values (0.3766 and 0.4156 at $\mathrm{pH} 1.9$ and 7.4 , respectively) were obtained in the Higuchi model compared to other drug release models, thus the drug release from the nanoformulation at both $\mathrm{pH}$ followed the Higuchi kinetic model.

Brunauer-Emmett-Teller surface area analysis

The $\mathrm{N}_{2}$ adsorption/desorption isotherms of the calcined MCM-41 and ABZ-loaded MCM-41 NPs are demonstrated in Fig. 6. MCM-41 and ABZ-loaded MCM-41 NPs demonstrated the behavior of the mesoporous material and type IV isotherm, based on the IUPAC isotherm classification system. These isotherms can be divided into three steps, including i) a linear increase in $\mathrm{N}_{2}$ adsorption, occurring at relatively low pressure owing to the monolayer adsorption of $\mathrm{N}_{2}$ on the wall of MCM-41 and ABZ-loaded MCM-41 NPs; ii) capillary condensation of $\mathrm{N}_{2}$ inside the mesopores, which is indicative of narrow pore size distribution; and iii) saturation step, presented as a long plateau at higher pressures owing to the low $\mathrm{N}_{2}$ adsorption onto the external surface of the calcined MCM-41 and ABZ-loaded MCM-41 NPs (32). Based on these results, the surface volume for MCM-41 and ABZ-loaded MCM-41 NPs was found to be 540 and $380 \mathrm{~m}^{2} / \mathrm{g}$, respectively, while the pore size for these formulations was found to be 2.5 and 2.1 $\mathrm{nm}$, respectively. In addition, the pore volume of MCM-41 and ABZ-loaded MCM-41 NPs was determined to be approximately 0.75 and $0.46 \mathrm{~cm}^{3} / \mathrm{g}$, respectively.

\section{Biological effects of the nanoparticles}


The cytotoxicity effects of ABZ, MCM-41, and ABZ-loaded MCM-41 NPs were investigated on HepG2 cells using MTT assay to determine if ABZ loading into NPs caused enhanced cytotoxicity effects or not. For this purpose, $A B Z$ at the concentrations of $0,3.1,6.3,12.5,25,50$, and $100 \mu \mathrm{M}$ were used as these concentrations encompass the reported serum concentration of $A B Z(4.3 \mu \mathrm{M})$, when administered at the standard doses $(10 \mathrm{mg} / \mathrm{kg} /$ day $)$. Also, a significantly higher drug concentration $(100 \mu \mathrm{M})$ was used to make the toxicity more pronounced. The results demonstrated that MCM-41 NPs, at the concentration of $25 \mu \mathrm{g} / \mathrm{mL}$, had no toxicity effects on the cells. It was found that ABZ loading into NPs caused a significant increase in the cytotoxicity effects of the drug in a concentration-dependent manner (Fig. 7), in which the $\mathrm{IC}_{50}$ values for $\mathrm{ABZ}$ and $\mathrm{ABZ}-\mathrm{MCM}-41 \mathrm{NPs}$ were estimated 23 and $7.9 \mu \mathrm{M}$, respectively.

Cell migration

Migration is a distinctive feature of cellular behavior that contributes to embryogenesis, tissue remodeling, wound healing, and pathologies, such as cancer metastasis and invasion $(24,25)$. The cell migration was determined using HepG2 cells at different time intervals to recognize the distance at which cancer cell invasion happened. A scratch with a width of $500 \mu \mathrm{m}$ was generated and treated with ABZ and ABZ-loaded MCM-41 NPs at the drug concentration of $25 \mu \mathrm{M}$. The cancer cell migration was monitored by taking pictures at times 0 and $24 \mathrm{~h}$ (Fig. 8). As the results demonstrated, both ABZ and ABZloaded MCM-41 NPs inhibited cell migration. However, ABZ-loaded MCM-41 NPs, compared to ABZ, seemed to be more potent to inhibit the migration as according to the observation, the scratch width corresponded to ABZ was less than that corresponded to ABZ-loaded MCM-41 NPs. This indicated the potency of MCM-41 NPs to increase the antiproliferative effects of ABZ. These results were in agreement with the results of cytotoxicity evaluation, where the NPs caused an increase in the cytotoxicity effects of ABZ against HepG2 cells.

\section{Conclusions}

Poorly water-soluble drugs have low absorption, and consequently, have low bioavailability (11), which causes a considerable decrease in the therapeutic response and an increase in the overall dose (2). ABZ has poor water solubility, and as a result, has low bioavailability (56). MSNPs are able to increase the solubility rate of poorly water-soluble drugs $(3,22)$. The present study aimed to increase the efficacy of ABZ against liver cancer cells through loading into MCM-41 NPs. The MCM-41 and ABZ-loaded MCM-41 NPs were successfully synthesized using CTAB as a precursor. The characterization results demonstrated that nanoscale size particles were constructed. Both NPs were monodisperse with high thermal stability. MCM-41 NPs demonstrated high potency for the loading of ABZ (with the drug loading efficiency of $30 \%$ ), which is a poorly water-soluble drug. This can cause a significant increase in ABZ solubility and, as a result, drug bioavailability. Also, ABZ-loaded MCM-41 NPs can significantly increase the cytotoxicity effects of $A B Z$ (by 2.6-fold) against liver cancer HepG2 cells. These results were in agreement with the results of the migration assay, where ABZ-loaded MCM-41 NPs, compared to ABZ, was more efficient to 
restrain the cell migration. Overall, the results of the present study suggest evaluating the efficacy of ABZloaded MCM-41 NPs in vivo environment.

\section{Declarations}

Acknowledgments This work was performed in the department of Pilot Nanobiotechnology of Pasteur Institute of Iran. Hereby thanks to all colleagues for their invaluable help.

Author Contributions All authors have accepted responsibility for the entire content of this manuscript and approved its submission.

Funding Information Not applicable.

Availability of Data and Material Not applicable.

\section{Compliance with Ethical Standards}

Conflict of Interest The authors declare that they have no competing interests.

Code Availability Not applicable.

\section{References}

1. Global Cancer Observatory. Available online: http://gco.iarc.fr (accessed on 27 September 2018).

2. Abu-Huwaij, R. T. (2018) Promising Polymeric Buccoadhesive Bilayered Tablets Releasing Valsartan: Effect of Gel Strength. Jordan Journal of Pharmaceutical Sciences, 11.

3. Adrover, M. E., Pedernera, M., Bonne, M., Lebeau, B., Bucalá, V. and Gallo, L. (2020) Synthesis and characterization of mesoporous SBA-15 and SBA-16 as carriers to improve albendazole dissolution rate. Saudi Pharmaceutical Journal,28, 15-24.

4. Alamdarnejad, G., Sharif, A., Taranejoo, S., Janmaleki, M., Kalaee, M. R., Dadgar, M. and Khakpour, M. (2013) Synthesis and characterization of thiolated carboxymethyl chitosan-graft-cyclodextrin nanoparticles as a drug delivery vehicle for albendazole. Journal of Materials Science: Materials in Medicine,24, 1939-1949.

5. Alavi, S. E., Koohi Moftakhari Esfahani, M., Alavi, F., Movahedi, F. and Akbarzadeh, A. (2013) Drug delivery of hydroxyurea to breast cancer using liposomes. Indian Journal of Clinical Biochemistry,28, 299-302.

6. Alavi, S. E., Koohi Moftakhari Esfahani, M., Ghassemi, S., Akbarzadeh, A. and Hassanshahi, G. (2014) In vitro evaluation of the efficacy of liposomal and pegylated liposomal hydroxyurea. Indian Journal of Clinical Biochemistry,29, 84-88.

7. Alavi, S. E., Muflih Al Harthi, S., Ebrahimi Shahmabadi, H. and Akbarzadeh, A. (2019) Cisplatin-loaded polybutylcyanoacrylate nanoparticles with improved properties as an anticancer agent. International 
journal of molecular sciences,20, 1531.

8. Bhandari, B. R. and Howes, T. (1999) Implication of glass transition for the drying and stability of dried foods. Journal of Food Engineering,40, 71-79.

9. Binti Haji Mat Syned, N. (2014) Microstructural studies of strontium titanate ceramic pressed at varying pressure.

10. Bray, F., Ferlay, J., Soerjomataram, I., Siegel, R. L., Torre, L. A. and Jemal, A. (2018) Global cancer statistics 2018: GLOBOCAN estimates of incidence and mortality worldwide for 36 cancers in 185 countries. CA: a cancer journal for clinicians,68, 394-424.

11. Chaudhari, S. P. and Handge, N. M. (2020) Formulation, Development and Evaluation of Lopinavir Loaded Polymeric Micelles. Journal of Science and Technology,5, 173-187.

12. Chen, L., Remondetto, G., Rouabhia, M. and Subirade, M. (2008) Kinetics of the breakdown of crosslinked soy protein films for drug delivery. Biomaterials,29, 3750-3756.

13. De Cicco, P., Catani, M. V., Gasperi, V., Sibilano, M., Quaglietta, M. and Savini, I. (2019) Nutrition and breast cancer: a literature review on prevention, treatment and recurrence. Nutrients, 11, 1514.

14. Deodhar, G. V., Adams, M. L. and Trewyn, B. G. (2017) Controlled release and intracellular protein delivery from mesoporous silica nanoparticles. Biotechnology journal,12, 1600408.

15. Dhome, A. G., Deshkar, S. S. and Shirolkar, S. V. (2018) Gliclazide solid lipid nanoparticles: formulation, optimization and in vitro characterization. Pharm Reson,1, 8-16.

16. Du, M., Chen, L., Zhao, J., Tian, F., Zeng, H., Tan, Y., Sun, H., Zhou, J. and Ji, Y. (2014) Microvascular invasion (MVI) is a poorer prognostic predictor for small hepatocellular carcinoma. BMC cancer, 14, 17.

17. Ebrahimi Shahmabadi, H., Movahedi, F., Koohi Moftakhari Esfahani, M., Alavi, S. E., Eslamifar, A., Mohammadi Anaraki, G. and Akbarzadeh, A. (2014) Efficacy of Cisplatin-loaded polybutyl cyanoacrylate nanoparticles on the glioblastoma. Tumor Biology,35, 4799-4806.

18. Fahr, A. and Liu, X. (2007) Drug delivery strategies for poorly water-soluble drugs. Expert opinion on drug delivery, 4, 403-416.

19. Fang, Y., Yang, W., Cheng, L., Meng, F., Zhang, J. and Zhong, Z. (2017) EGFR-targeted multifunctional polymersomal doxorubicin induces selective and potent suppression of orthotopic human liver cancer in vivo. Acta biomaterialia,64, 323-333.

20. Ghaferi, M., Amari, S., Mohrir, B. V., Raza, A., Shahmabadi, H. E. and Alavi, S. E. (2020) Preparation, Characterization, and Evaluation of Cisplatin-Loaded Polybutylcyanoacrylate Nanoparticles with Improved In Vitro and In Vivo Anticancer Activities. Pharmaceuticals,13, 44.

21. Ghaferi, M., Asadollahzadeh, M. J., Akbarzadeh, A., Ebrahimi Shahmabadi, H. and Alavi, S. E. (2020) Enhanced efficacy of PEGylated liposomal cisplatin: In vitro and in vivo evaluation. International Journal of Molecular Sciences,21, 559.

22. Ghaferi, M., Koohi Moftakhari Esfahani, M., Raza, A., Al Harthi, S., Ebrahimi Shahmabadi, H. and Alavi, S. E. (2021) Mesoporous silica nanoparticles: synthesis methods and their therapeutic use- 
recent advances. Journal of Drug Targeting,29, 131-154.

23. Giraldo, L., Rodriguez-Estupiñán, P. and Moreno-Piraján, J. C. (2019) Isosteric heat: comparative study between Clausius-Clapeyron, CSK and adsorption calorimetry methods. Processes,7, 203.

24. Glenn, H. L., Messner, J. and Meldrum, D. R. (2016) A simple non-perturbing cell migration assay insensitive to proliferation effects. Scientific reports,6, 1-12.

25. Grada, A., Otero-Vinas, M., Prieto-Castrillo, F., Obagi, Z. and Falanga, V. (2017) Research techniques made simple: analysis of collective cell migration using the wound healing assay. Journal of Investigative Dermatology,137, e11-e16.

26. He, Y., Ye, Z., Liu, X., Wei, Z., Qiu, F., Li, H.-F., Zheng, Y. and Ouyang, D. (2020) Can machine learning predict drug nanocrystals? Journal of Controlled Release,322, 274-285.

27. Ho, D. N. (2014), in Cancer Theranostics, Elsevier, pp. 255-268.

28. Ibrahim, A. H., Smått, J.-H., Govardhanam, N. P., Ibrahim, H. M., Ismael, H. R., Afouna, M. I., Samy, A. M. and Rosenholm, J. M. (2020) Formulation and optimization of drug-loaded mesoporous silica nanoparticle-based tablets to improve the dissolution rate of the poorly water-soluble drug silymarin. European Journal of Pharmaceutical Sciences,142, 105103.

29. Jafari, S., Maleki-Dizaji, N., Barar, J., Barzegar-Jalali, M., Rameshrad, M. and Adibkia, K. (2016) Physicochemical characterization and in vivo evaluation of triamcinolone acetonide-loaded hydroxyapatite nanocomposites for treatment of rheumatoid arthritis. Colloids and Surfaces B: Biointerfaces, 140, 223-232.

30. Jiao, Y., Li, Y., Jiang, P., Fu, Z. and Liu, Y. (2019) High MAST2 mRNA expression and its role in diagnosis and prognosis of liver cancer. Scientific Reports,9, 1-10.

31. Kavousi, F., Goodarzi, M., Ghanbari, D. and Hedayati, K. (2019) Synthesis and characterization of a magnetic polymer nanocomposite for the release of metoprolol and aspirin. Journal of Molecular Structure, 1183, 324-330.

32. Khezri, K., Haddadi-Asl, V. and Roghani-Mamaqani, H. (2014) Introduction of a double bond containing modifier on the surface of MCM-41 nanoparticles: application for SR\&NI ATRP of styrene. Nano,9, 1450023.

33. Koohi Moftakhari Esfahani, M., Alavi, S. E., Akbarzadeh, A., Ghassemi, S., Saffari, Z., Farahnak, M. and Chiani, M. (2014) Pegylation of nanoliposomal paclitaxel enhances its efficacy in breast cancer. Tropical Journal of Pharmaceutical Research,13, 1195-1198.

34. Li, H., Pan, Y., Farmakes, J., Xiao, F., Liu, G., Chen, B., Zhu, X., Rao, J. and Yang, Z. (2019) A sulfonated mesoporous silica nanoparticle for enzyme protection against denaturants and controlled release under reducing conditions. Journal of colloid and interface science,556, 292-300.

35. Li, M.-M., Tang, Y.-Q., Gong, Y.-F., Cheng, W., Li, H.-L., Kong, F.-E., Zhu, W.-J., Liu, S.-S., Huang, L. and Guan, X.-Y. (2019) Development of an oncogenic dedifferentiation SOX signature with prognostic significance in hepatocellular carcinoma. BMC cancer, $19,851$.

36. Liu, H., Sun, H., Zhang, B., Liu, S., Deng, S., Weng, Z., Zuo, B., Yang, J. and He, Y. (2020) 18 F-FDG PET imaging for monitoring the early anti-tumor effect of albendazole on triple-negative breast cancer. 
Breast Cancer,27, 372-380.

37. Liu, M., Zhang, X., Yang, B., Deng, F., Ji, J., Yang, Y., Huang, Z., Zhang, X. and Wei, Y. (2014) Luminescence tunable fluorescent organic nanoparticles from polyethyleneimine and maltose: facile preparation and bioimaging applications. RSC advances,4, 22294-22298.

38. Mahmood, Y., Khan, I. U., Shahzad, Y., Khan, R. U., Khalid, S. H., Yousaf, A. M., Hussain, T., Asghar, S., Khalid, I. and Asif, M. (2020) Amino-decorated mesoporous silica nanoparticles for controlled sofosbuvir delivery. European Journal of Pharmaceutical Sciences, 143, 105184.

39. Maleki, A., Kettiger, H., Schoubben, A., Rosenholm, J. M., Ambrogi, V. and Hamidi, M. (2017) Mesoporous silica materials: From physico-chemical properties to enhanced dissolution of poorly water-soluble drugs. Journal of Controlled Release,262, 329-347.

40. Marzbani, B., Nazari, J., Najafi, F., Marzbani, B., Shahabadi, S., Amini, M., Moradinazar, M., Pasdar, Y., Shakiba, E. and Amini, S. (2019) Dietary patterns, nutrition, and risk of breast cancer: a case-control study in the west of Iran. Epidemiology and health,41, e2019003.

41. Mehmood, A., Ghafar, H., Yaqoob, S., Gohar, U. F. and Ahmad, B. (2017) Mesoporous silica nanoparticles: a review. Journal of Developing Drugs,6, 1000174.

42. Momenimovahed, Z. and Salehiniya, H. (2019) Epidemiological characteristics of and risk factors for breast cancer in the world. Breast Cancer: Targets and Therapy,11, 151.

43. Movahedi, F., Ebrahimi Shahmabadi, H., Alavi, S. E. and Koohi Moftakhari Esfahani, M. (2014) Release modeling and comparison of nanoarchaeosomal, nanoliposomal and pegylated nanoliposomal carriers for paclitaxel. Tumor Biology,35, 8665-8672.

44. Nguyen, C. T., Webb, R. I., Lambert, L. K., Strounina, E., Lee, E. C., Parat, M.-O., McGuckin, M. A., Popat, A., Cabot, P. J. and Ross, B. P. (2017) Bifunctional succinylated $\varepsilon$-polylysine-coated mesoporous silica nanoparticles for $\mathrm{pH}$-responsive and intracellular drug delivery targeting the colon. ACS Applied Materials \& Interfaces,9, 9470-9483.

45. Noorani, L., Stenzel, M., Liang, R., Pourgholami, M. H. and Morris, D. L. (2015) Albumin nanoparticles increase the anticancer efficacy of albendazole in ovarian cancer xenograft model. Journal of nanobiotechnology, 13, 1-12.

46. Pandey, P. K., Sharma, A. K., Rani, S., Mishra, G., Kandasamy, G., Patra, A. K., Rana, M., Sharma, A. K., Yadav, A. K. and Gupta, U. (2018) MCM-41 nanoparticles for brain delivery: better choline-esterase and amyloid formation inhibition with improved kinetics. ACS Biomaterials Science \& Engineering,4, 2860-2869.

47. Patel, K., Doudican, N. A., Schiff, P. B. and Orlow, S. J. (2011) Albendazole sensitizes cancer cells to ionizing radiation. Radiation Oncology,6, 160.

48. Pavan Kumar, M., Madhusudan Rao, Y. and Apte, S. (2007) Improved bioavailability of albendazole following oral administration of nanosuspension in rats. Current Nanoscience,3, 191-194.

49. Porta-i-Batalla, M., Eckstein, C., Xifré-Pérez, E., Formentín, P., Ferré-Borrull, J. and Marsal, L. F. (2016) Sustained, controlled and stimuli-responsive drug release systems based on nanoporous anodic alumina with layer-by-layer polyelectrolyte. Nanoscale research letters,11, 1-9. 
50. Pourgholami, M., Woon, L., Almajd, R., Akhter, J., Bowery, P. and Morris, D. (2001) In vitro and in vivo suppression of growth of hepatocellular carcinoma cells by albendazole. Cancer letters, 165, 43-49.

51. Rabinel, P., Dousse, D., Muscari, F. and Suc, B. (2017) Management of liver cancer. The Surgeon's point of view. Reports of Practical Oncology \& Radiotherapy,22, 176-180.

52. Rahikkala, A., Pereira, S. A., Figueiredo, P., Passos, M. L., Araújo, A. R., Saraiva, M. L. M. and Santos, H. A. (2018) Mesoporous silica nanoparticles for targeted and stimuli-responsive delivery of chemotherapeutics: A review. Advanced Biosystems,2, 1800020.

53. Ramezani Farani, M., Khadiv-Parsi, P., Riazi, G. H., Shafiee Ardestani, M. and Saligheh Rad, H. (2020) PEGylation of graphene/iron oxide nanocomposite: assessment of release of doxorubicin, magnetically targeted drug delivery and photothermal therapy. Applied Nanoscience, 1-13.

54. Ramezani Farani, M., Khadive Parsi, P., Riazi, G., Shafiee Ardestani, M. and Saligeh Rad, H. (2019) Extending the application of a magnetic PEG three-part drug release device on a graphene substrate for the removal of Gram-positive and Gram-negative bacteria and cancerous and pathologic cells. Drug design, development and therapy,13,1581.

55. Raza, A., Sime, F. B., Cabot, P. J., Maqbool, F., Roberts, J. A. and Falconer, J. R. (2019) Solid nanoparticles for oral antimicrobial drug delivery: A review. Drug Discovery Today, 24, 858-866.

56. Savio, E., Dominguez, L., Malanga, A., Quevedo, D., Saldana, J., Camarote, C., Ochoa, A. and Fagiolino, P. (1998) Lipidic matrix of albendazole: an alternative for systemic infections. Bollettino Chimico Farmaceutico, 137, 345-349.

57. Soheyla Honary, Hamed Barabadi, Hamed Barabadi, Gharaei Gharaei and Naghibi, F. (2013) Green Synthesis of Silver Nanoparticles Induced by theFungus Penicillium citrinum. Tropical Journal of Pharmaceutical Research,12, 7-11.

58. Tawfeek, G. M., Baki, M. H. A., Ibrahim, A. N., Mostafa, M. A. H., Fathy, M. M. and Diab, M. S. E. D. M. (2019) Enhancement of the therapeutic efficacy of praziquantel in murine Schistosomiasis mansoni using silica nanocarrier. Parasitology research,118, 3519-3533.

59. Tzankova, V., Aluani, D., Yordanov, Y., Valoti, M., Frosini, M., Spassova, I., Kovacheva, D. and Tzankov, B. (2019) In vitro toxicity evaluation of lomefloxacin-loaded MCM-41 mesoporous silica nanoparticles. Drug and Chemical Toxicology, 1-12.

60. Vazhayal, L., Talasila, S., Abdul Azeez, P. M. and Solaiappan, A. (2014) Mesochanneled hierarchically porous aluminosiloxane aerogel microspheres as a stable support for $\mathrm{pH}$-responsive controlled drug release. ACS Applied Materials \& Interfaces,6, 15564-15574.

61. Yao, Y., Zhang, M., Shi, J., Gong, M., Zhang, H. and Yang, Y. (2001) Encapsulation of fluorescein into MCM-41 mesoporous molecular sieve by a sol-gel method. Materials Letters,48, 44-48.

62. Zeleňák, V., Halamová, D., Almáši, M., Žid, L., Zeleňáková, A. and Kapusta, O. (2018) Ordered cubic nanoporous silica support MCM-48 for delivery of poorly soluble drug indomethacin. Applied Surface Science, $\mathbf{4 4 3}, \mathbf{5 2 5 - 5 3 4 .}$

\section{Figures}




\section{MCM-41}
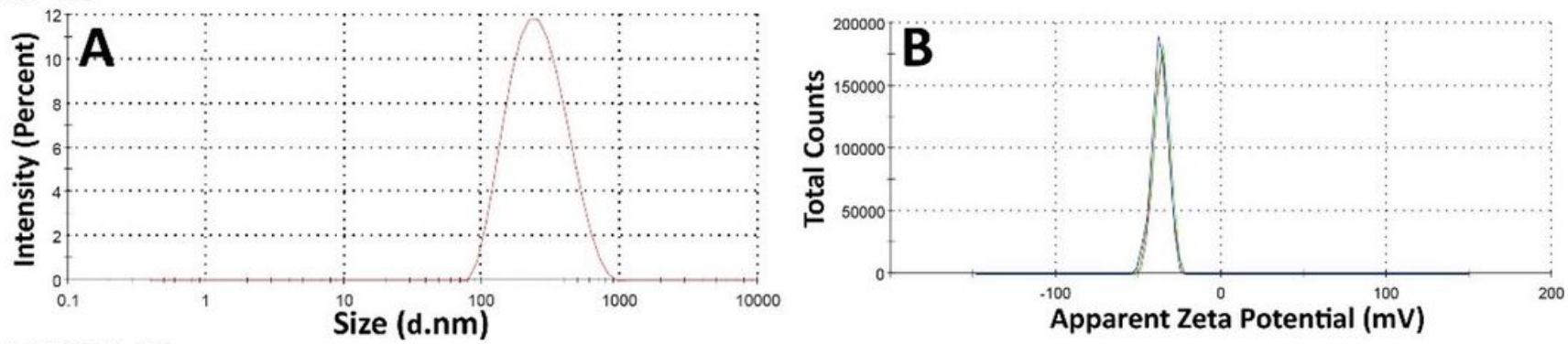

ABZ-MCM-41
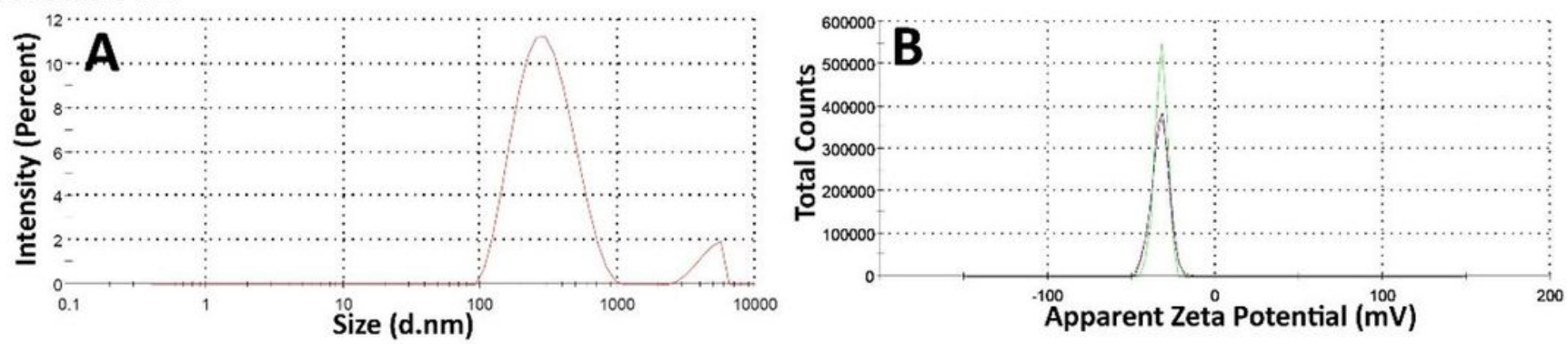

\section{Figure 1}

A) Hydrodynamic diameter and B) zeta potential of MCM-41 and ABZ-loaded MCM-41 NPs, measured by the DLS method. As the results demonstrated, both NP formulations were formed at the nanoscale size (220 \pm 11.5 and $293 \pm 8.7 \mathrm{~nm}$ for MCM-41 and ABZ-loaded MCM-41 NPs, respectively). Also, as the Figure shows, both NPs have negative zeta potential equal to $-36.3 \pm 4.57$ and $-33.0 \pm 4.93 \mathrm{mV}$, respectively
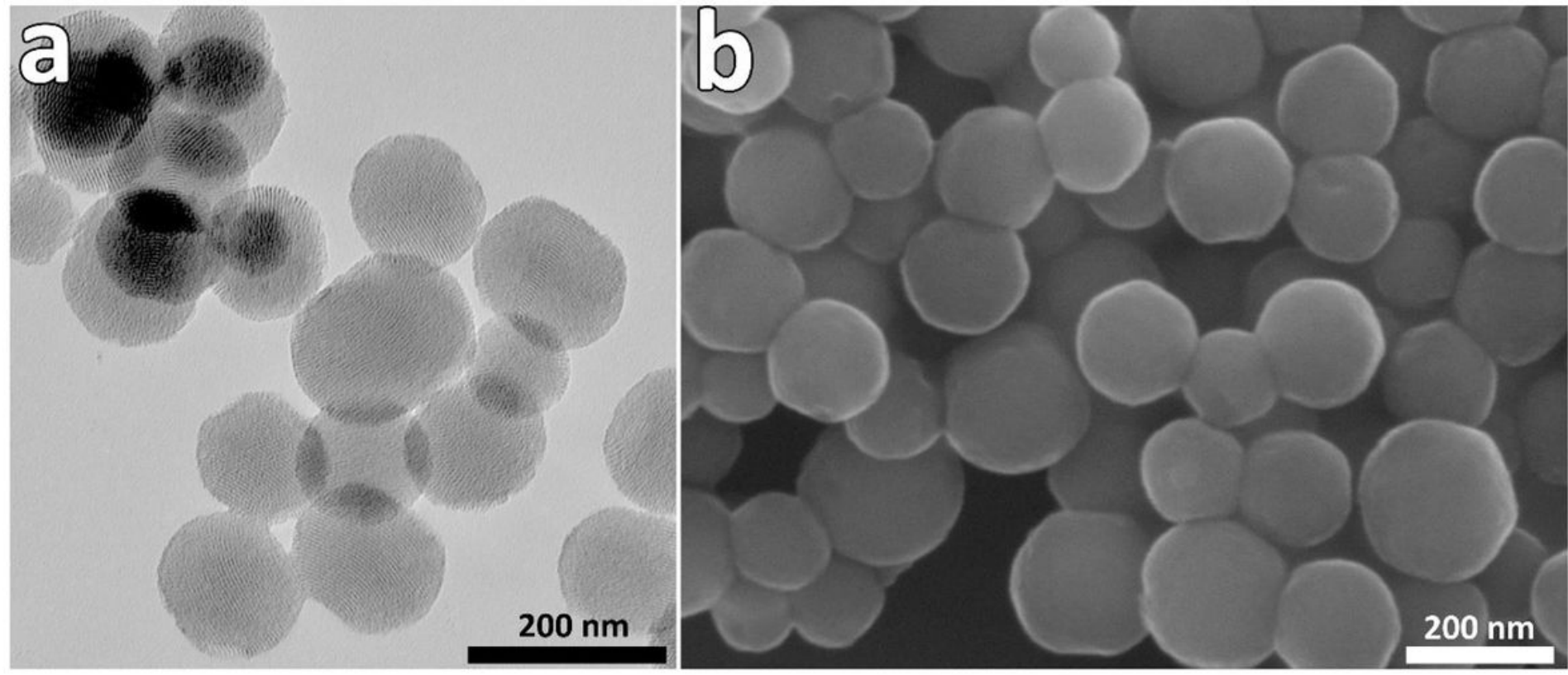

\section{Figure 2}

A) Hydrodynamic diameter and B) zeta potential of MCM-41 and ABZ-loaded MCM-41 NPs, measured by the DLS method. As the results demonstrated, both NP formulations were formed at the nanoscale size 
(220 \pm 11.5 and $293 \pm 8.7 \mathrm{~nm}$ for MCM-41 and ABZ-loaded MCM-41 NPs, respectively). Also, as the Figure shows, both NPs have negative zeta potential equal to $-36.3 \pm 4.57$ and $-33.0 \pm 4.93 \mathrm{mV}$, respectively

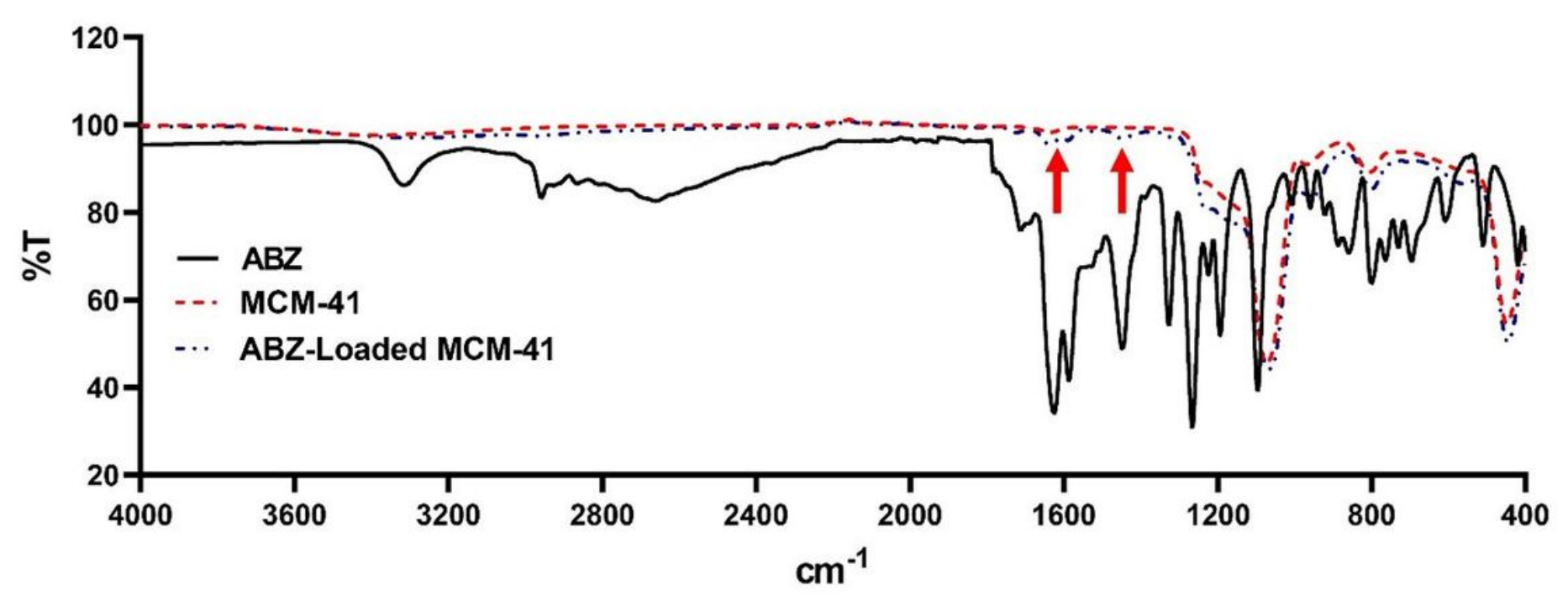

Figure 3

FTIR spectra of ABZ, MCM-41, and ABZ-loaded MCM-41 NPs. The peaks related to pure ABZ (e.g., 1623 $\mathrm{cm}-1$, demonstrate by arrows) were observed in the spectrum of ABZ-loaded MCM-41 NPs, confirming that ABZ was loaded into the NPs. Also, as the ABZ-related peaks remained intact in ABZ-loaded MCM-41 NPs, it can be concluded that the drug was loaded into these NPs physically 

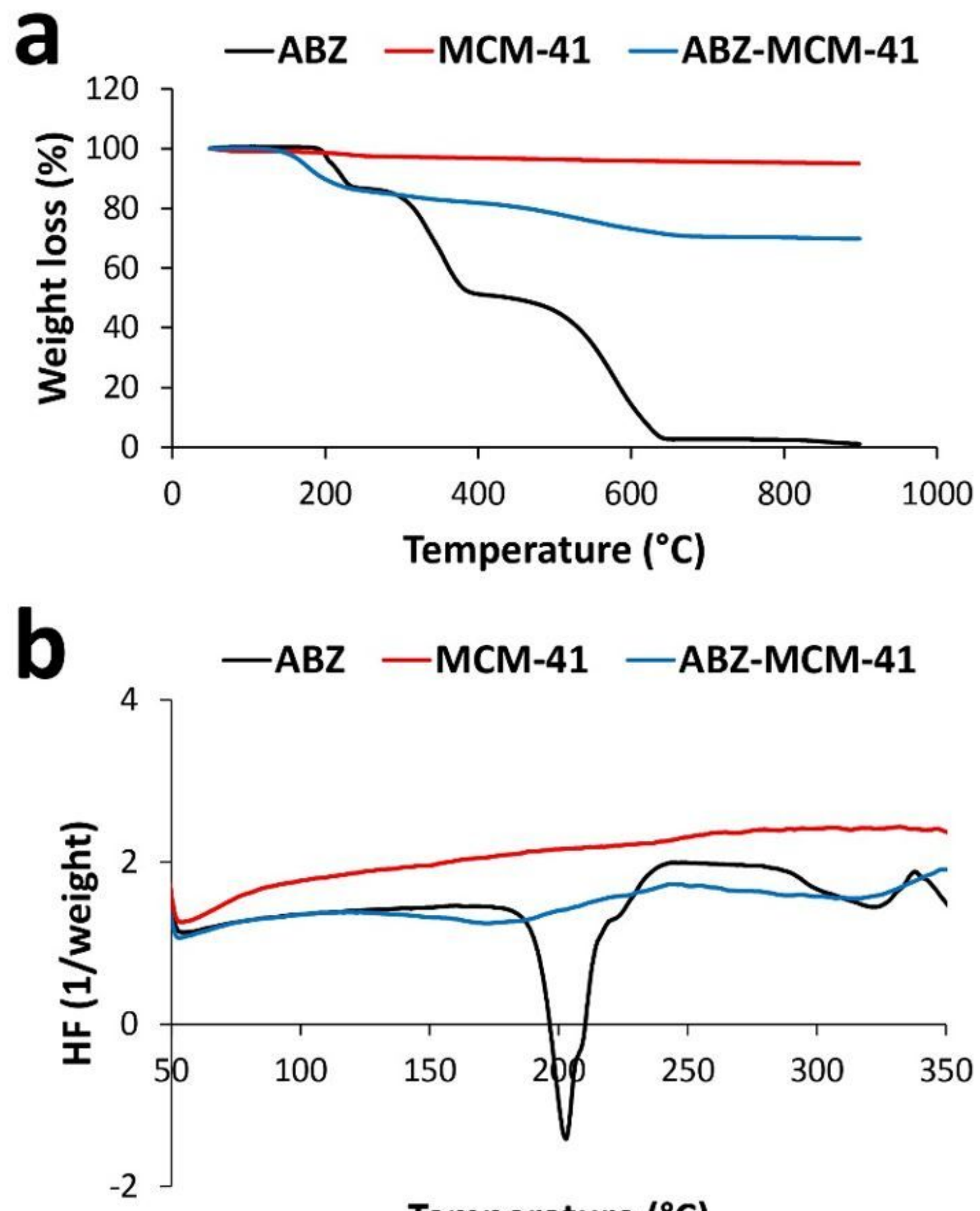

Temperature $\left({ }^{\circ} \mathrm{C}\right)$

Figure 4

a) TGA thermograms of ABZ, MCM-41, and ABZ-loaded NPs and b) DSC profiles of ABZ, MCM-41, and ABZ-MCM-41 NPs. Panel a shows, MCM-41 NPs experienced an initial weight loss at $250{ }^{\circ} \mathrm{C}$, resulting in approximately $3 \%$ weight loss. ABZ-loaded NPs were also decomposed at two temperatures, 150 and 450 ${ }^{\circ} \mathrm{C}$, and this decomposition led to a decrease of $30 \%$ in the mass of the formulation. In addition, ABZ was completely degraded when the temperature reached $900^{\circ} \mathrm{C}$. In panel b), pure ABZ showed a melting 
endothermic peak around $200{ }^{\circ} \mathrm{C}$, while there were no obvious peaks in the thermogram of MCM-41 NPs. A melting endothermic peak but not sharp was also observed in the thermogram of ABZ-MCM-41 NPs at around $170{ }^{\circ} \mathrm{C}$, which could be attributed to the crystalline anhydrous state of $A B Z$

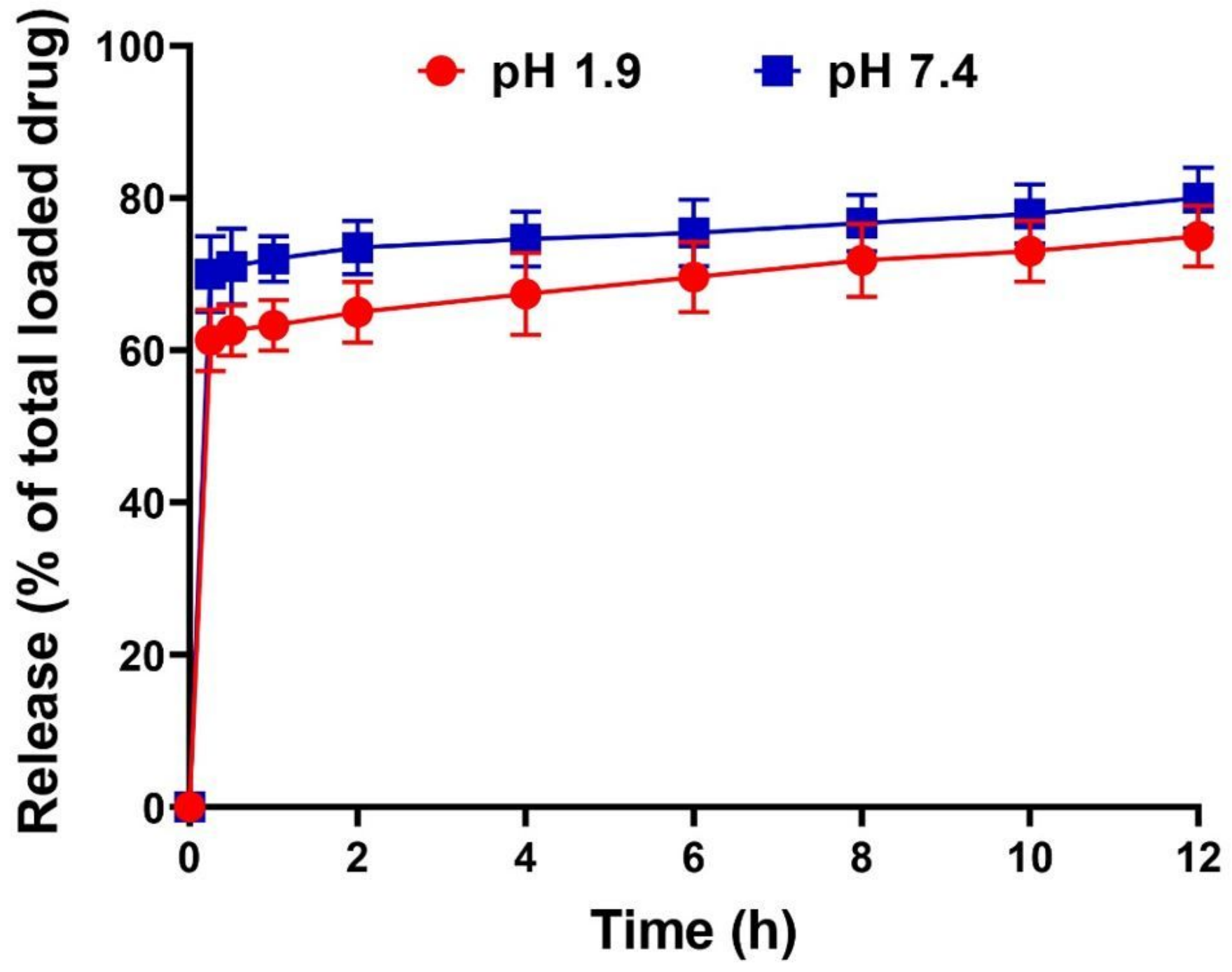

Figure 5

The cumulative percentage of ABZ release versus time from ABZ-loaded MCM-41 NPs at pH 1.9 and 7.4. As the results showed, a burst drug release from the NPs occurred at the first 15 min of the study, leading to the release of 62 and $70 \%$ of the loaded drug at $\mathrm{pH} 1.9$ and 7.2, respectively. The release was then continued with a sustained and controlled release in the remaining time of the study. Statistical analyses were performed using one-way analysis of variance (ANOVA) and F-tests. The data are expressed as mean $\pm S D(n=3)$ 

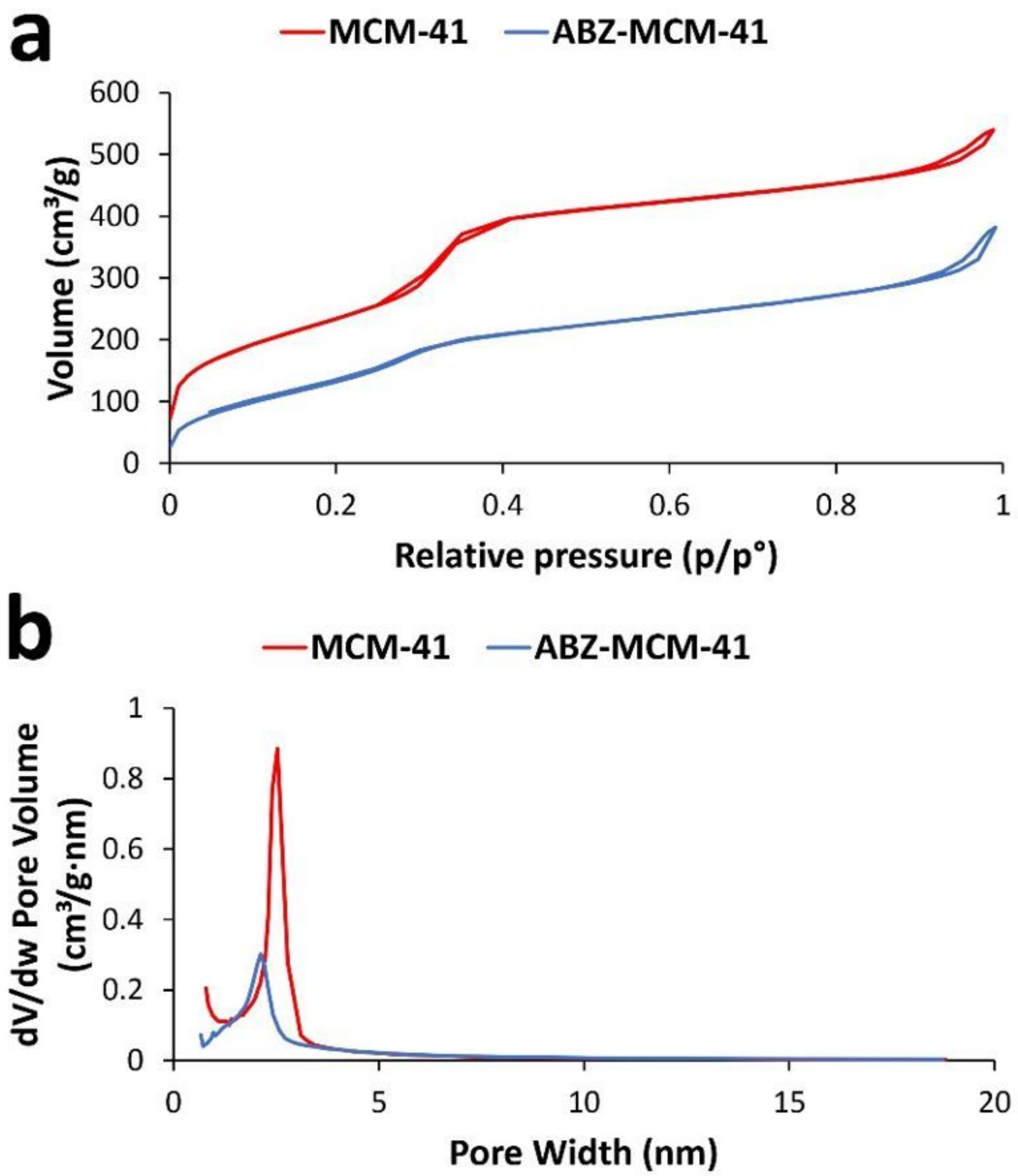

Figure 6

N2 adsorption/desorption isotherms of MCM-41 and ABZ-MCM-41 NPs for measuring their a) surface volume and $b$ ) pore size. As the results showed, a sharp increase in the N2 uptake around $p / p * 0.3$ occurred, which could be attributed to capillary condensation in cylindrical pores of MCM-41 and ABZloaded MCM-41 NPs. Also, the surface volume and pore size of the carrier decrease after drug loading. However, this decrease does not affect the mesoporous structure of this carrier 


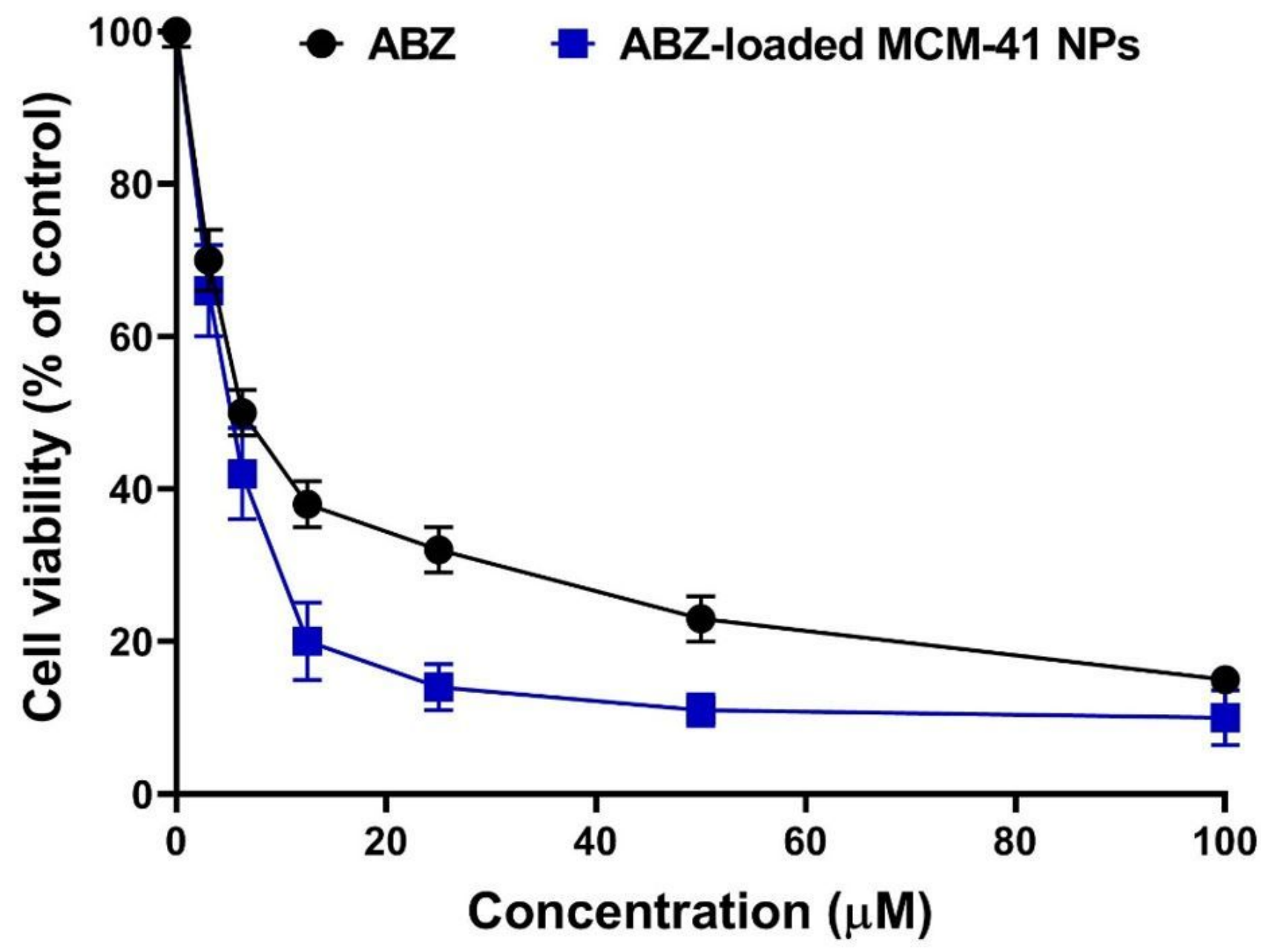

Figure 7

Cell viability effects of ABZ and ABZ-loaded MCM-41 NPs on HepG2 liver cancer cells after $24 \mathrm{~h}$. As the Figure demonstrates, the loading of ABZ into MCM-41 NPs caused a significant reduction in HepG2 cell viability compared to that of the standard drug. The data were expressed as mean $\pm \operatorname{SD}(n=3)$ 

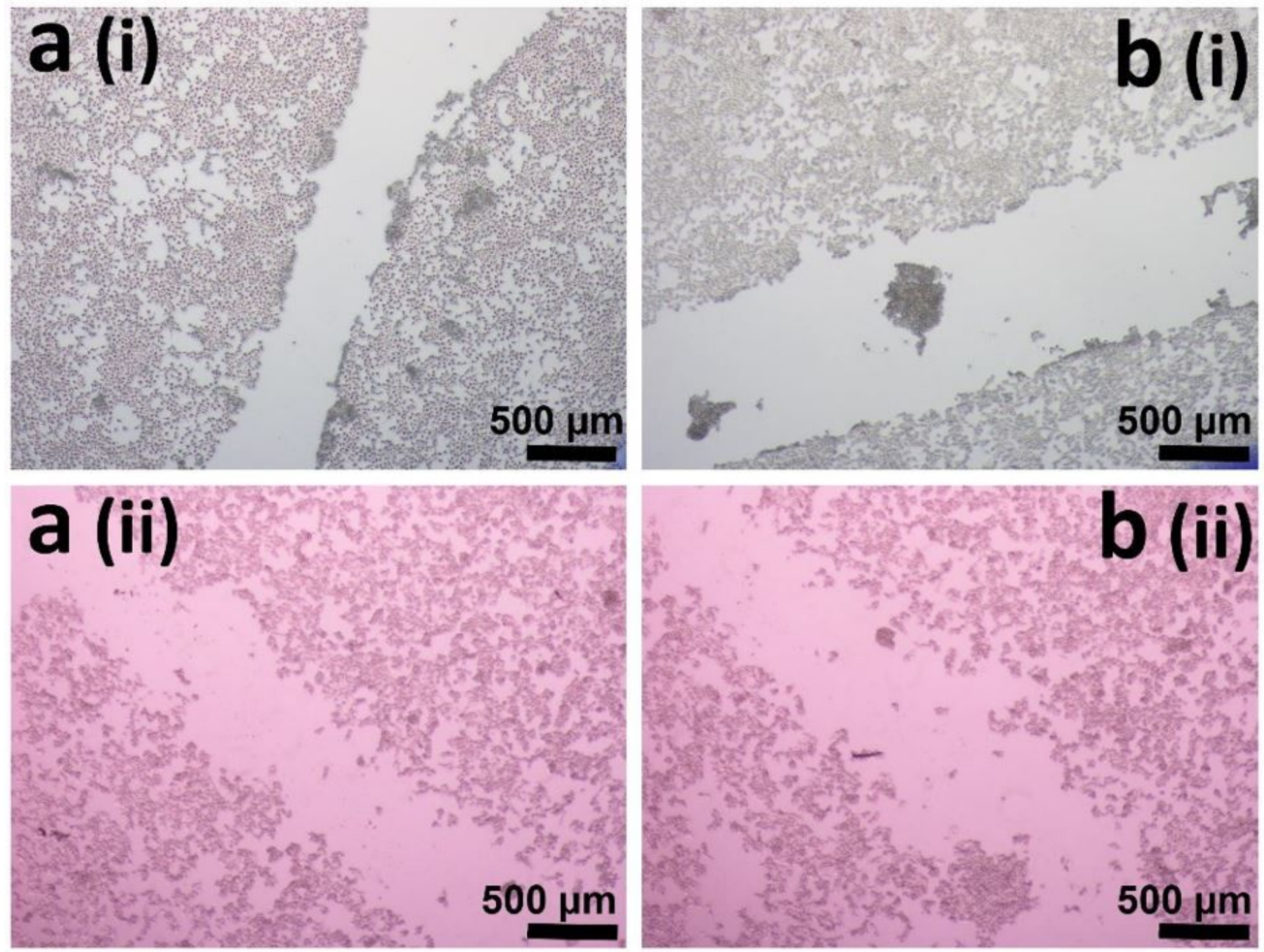

\section{Figure 8}

Effects of a) ABZ and b) ABZ-loaded MCM-41 NPs on the HepG2 cells migration at i) before ( $0 \mathrm{~h})$ and ii) after $(24 \mathrm{~h}$ ) cell treatment. Both ABZ and ABZ-loaded MCM-41 NPs restrained the cell migration and, as a result, cancer cell invasion. However, ABZ-loaded MCM-41 NPs compared to ABZ were more potent to inhibit cell migration

\section{Supplementary Files}

This is a list of supplementary files associated with this preprint. Click to download.

- scheme1.jpg 